\title{
STUDY ON THE SUSTAINABLE PROJECT MANAGEMENT
}

\begin{tabular}{|c|c|c|c|}
\hline \multicolumn{4}{|c|}{$\begin{array}{l}\text { Sachin Gupta } \\
\text { ersity, Mathura, }\end{array}$} \\
\hline Journal & \multicolumn{3}{|c|}{$\begin{array}{l}\text { Samvakti Journal of Research in Business Management } \\
\text { https://www.sjrbm. samvaktijournals.com } \\
\text { Volume } 2 \text { Year of Volume 2021 Page No : } 9 \text { - } 16\end{array}$} \\
\hline Discipline & \multicolumn{3}{|c|}{ Business Management } \\
\hline Conference & \multicolumn{3}{|c|}{$\begin{array}{l}\text { A virtual international conference on redefining and transforming the role of higher } \\
\text { education in sustainable development }\end{array}$} \\
\hline Conference & \multicolumn{3}{|c|}{ Start Date: September 30, 2021} \\
\hline Dates & \multicolumn{3}{|c|}{ End Date : September 30, 2021} \\
\hline Institute Name & \multicolumn{3}{|c|}{$\begin{array}{l}\text { JAIN (Deemed-to-be University) in association with Council for Industrial } \\
\text { Innovation and Research }\end{array}$} \\
\hline $\begin{array}{l}\text { Date Received } \\
\text { ID } \\
\text { Dol }\end{array}$ & $\begin{array}{l}\text { : November } 19,2021 \\
: 2021.01 .13 \\
: 10.46402 / 2021.01 .13\end{array}$ & $\begin{array}{l}\text { Publication Date } \\
\text { Paper Type } \\
\text { Dol URL }\end{array}$ & $\begin{array}{l}\text { : December 12, } 2021 \\
\text { : Conference Paper } \\
: \text { https://dx.doi.org/10.46402/2021.01.13 }\end{array}$ \\
\hline
\end{tabular}

\section{ABSTRACT}

Among the most pressing concerns of our time is the need to address sustainability in ongoing projects, including financial, social, and sustainable development. As a result of the growing emphasis on sustainable business operations, scholars as well as the professional community's opinions about project management have altered. Today, the relevance of sustainable in business operations, as well as the stability of natural and environmental elements, is critical, which has influenced project management activities such as conceptualization, budgeting, scheduling, and implementation. This research does a literature assessment on diverse topics impacting project management sustainability from 1987 to 2018 . The current study also identifies and discusses possible futures for using computational processes to approximate and optimize sustainability challenges in project management. For example, after taking into account important aspects of sustainability practices, supercomputing evolutionary algorithms can utilized to build the number of co issue. A new integrated framework is also identified and presented, which includes a feedback function for evaluating each choice and action done to ensure the projects' long-term viability. 
KEYWORDS: Business, Sustainability, Sustainability Challenges, Sustainable Project Management.

\section{INTRODUCTION}

It is vital to assess and solve sustainability concerns in every part of the organization to achieve a long and productive organizational life in spite of ever-increasing challenges and natural resource scarcity. In the domain in project management, several scholars have looked at the themes of sustainable \& project management independently. However, only a modest amount of work has gone into developing new approaches for evaluating and implementing long-term site management. Sustainability ensures and integrates financial, social, and environmental responsibility components in order to prudently exploit current resources while also ensuring that future generations have access to the same. There are still conceptual and technological difficulties to be resolved for long-term project management. Green themes should be incorporated into methodologies for analyzing and evaluating sustainability, such as reducing pollution and continuous quality improvement. All project stakeholders should decide their goals after assessing the effects of the project's life on the project's overall sustainability. Furthermore, while making crucial project management decisions, the assessment of sustainability should include some critical metrics that may be used to quantify sustainability and can play a decisive and accessible role for all stakeholders. This study looked at and presented the literature on sustainability concerns in managing projects from 1987 to $2018^{[1]}$.

\section{Sustainability in projects:}

According to this outcomes of the writing review, the majority of researchers approached sustainability in the research from a different perspective in terms of the triple bottom line approach. Some scholars promote sustainability or "green" building assignments, project management, as well as the combination of financial and natural variables in their research. Research on development projects, on the other hand, focuses mostly on social aspects $^{[2]}$. Some scholars also discussed their work on integrating stability into project administration using social, environmental and economic approach and listed a number of variables from various perspectives. The previously mentioned development of financial, natural, and social variables in managing projects does not give a holistic approach to project management sustainability. For Brazilian businesses, an empirical analysis based on triple bottom line factors was conducted. The applicability of the triple Bottom line approach, according to the authors, is mostly determined by the project's strategy and viewpoint, which might be different from one assignment to next. As a result, there is a need to fill a gap in the creation of widely accepted sustainability metrics that can be useful to the vast mainstream of assignments to assess and evaluate their 
potential for long-term viability. The following are some parameters for incorporating sustainability into project management that have been found by various scholars ${ }^{[3]}$.

\section{Lifecycle of a Project:}

In the area of managing projects, many scholars debated the sustainable orientation. The project lifecycle is connected to the sustainability orientation, which has some limits for short-term projects. Because the project lifetime is constantly linked to the product or deliverable that is created as a result of the project, the deliverable lifespan and end product life cycle must also be considered in determining project sustainability. After considering the project process, deliverables, and impact, a broad discussion on sustainable project management is held.

\section{Projects at the regional, national, and international levels:}

The project's location is crucial in determining its long-term viability. Today's global economies are extremely sensitive to losses and gains, thus determining and assessing the sustainability implications at the regional, national, and worldwide levels has become critical to be competitive, companies are impacted by a variety of global guidelines, international partners, international stakeholders, international suppliers, and international clients, among other things. This can be connected to the global supply of goods and resources, as well as the international application of skills to projects spread across the country or internationally. As a result, from the project management perspective sustainability, it is always required to assess the project's level, i.e. whether initiative is regional, nationwide, or international ${ }^{[4]}$.

\section{Ethicality in projects:}

The assignment should be accomplished with an eye toward upholding the initiative's ethical and social objectives. In their studies for program management sustainable, a lot of scholars evaluated ethical and social principles. Ethics and Professional Conduct Codes', which also underlines the importance of considering and incorporating ethics and values into initiatives. The following parameters are still mostly respected by the global project managing fraternity, according to the standard project management code (2010): Fairness, Trustworthiness, Accountability, and Admiration.

\section{Projects should have clear policies and procedures:}

The openness with which a firm formulates its rules, procedures, makes decisions, and takes actions on numerous day-to-day challenges is demonstrated by the clear rules and processes aimed at projects in a corporation. Furthermore, it denotes in what way a company's policies and decisions will impact the environment and society [5]. It also shows that the organization is transparent and accountable about its policies, procedures, 
activities, and decisions, as well as the impact they have on the business, stakeholders, environment, and community. The corporation will be held liable for the consequences of its guidelines and processes. The company's strong policies indicate that strong and appropriate data would be delivered to investors, associates, and clients on a timely basis so that every investors and clients may examine, estimate, and reply to any critical problem. Companies may recycle waste in project management by having defined rules, procedures, and liability towards them. Corporations should be crystal clear, also proactive in their interaction by way of all investors to attain stability in project management. They must also consider the consequences on nature and society in the short and long term.

\section{Consideration for stakeholder's interest:}

From the standpoint of sustainability practices, stakeholder engagement and cooperation are critical. Stakeholder interests in projects are appropriately considered, which aids bilateral 160 statement in project management as well as contributes to entire investor management. Management should make an effort to include, encourage, and support stakeholder involvement in their projects. All project management techniques must be reflected in the stakeholder participation. One of the most important prerequisites for Project Company's long-term viability is active stakeholder participation (ISO, 2010). Effective stakeholder participation necessitates bidirectional and open communication, as well as the formation of a shared agenda between all stakeholders. As partners, the stakeholders can recognize the project's trouble spots and work together to develop solutions to those issues. Stakeholders can put solutions in place and track the progress of the projects ${ }^{[6]}$.

\section{LITERATURE REVIEW}

J. Kivilä et al. discussed as stakeholder's demand morally, organic, also financial efficiency throughout a life process, sustainability is becoming increasingly crucial in project implementation. Previous research has mostly concentrated on the environmental implications of project outputs, with little emphasis paid to bearable project management throughout assignment delivery. The purpose of this research is to determine which control techniques the project business employs for long-term project management. The precise and specific study focused on a major infrastructure project that included numerous partners in an alliance contract as well as the construction of a road tunnel in a difficult terrain. The findings show that maintainable task management is achieved not just through indicators, on the other hand also through a holistic regulator package that uses diverse control methods for diverse sustainability characteristics. Internal project control is supplemented by long-term project governance, which connects the project to 
outside investors and guidelines. The association contract encourages partners to take advantage of new prospects for economic, environmental, and social sustainability ${ }^{[7]}$.

Schipper et al. looked into it. Sustainability is one of the most pressing issues of our time, and businesses are beginning to incorporate sustainability principles into their operations. This integration necessitates change, and projects as agents of change are critical to long-term development. Integrating sustainability considerations into project management approaches is a hot topic right now. These techniques recommend creating a Sustainability Management Plan (SMP) as a document that reflects a project's sustainability perspective and required course of action. However, these techniques provide no guidance and support in developing such an SMP. To provide a useful tool, this paper proposes a Sustainable Project Management Canvas that may be used to assist a project manager and his project team in developing an SMP[8].

Sustainability, according to Silvius et al., is one of the most pressing issues of our day. Sustainability is being incorporated into marketing, business communication, yearly reports, and company operations. Projects performs a critical character in the implementation of additional bearable corporate practices, and a rising numerous studies link project management to the notion of sustainability. Sustainability, on the other hand, is intuitively recognized yet difficult to define in tangible, operational words. It's also difficult to put the emerging concept of sustainable project management into practice. The availability of an instrument for assessing and developing the addition of stability in assignments or project management remains a requirement for this operationalization. This study develops the 'Healthy Maturity Assessment Model' as a practical 'tool' for assessing and developing project sustainability practices. Organizations can use this maturity model to integrate abstract and interpretive principles of sustainable development into concrete activities in their projects and track their progress ${ }^{[9]}$.

Moehler et al. looked into Addition of sustainability hooked on corporate practices and organizational policy necessitates a rethinking of operations management. As project management becomes more important in corporate and culture, the query becomes whether present program organization descriptions, methodologies, procedures, practices, and data zones are suitable for providing long-term results. The effect of sustainability on project administration methodologies, procedures, practices, and information zones will be examined. A comparison of assessment of this literature can help in the creation of a deep knowledge of this issues confronted by way of the discipline in moving on the way to "sustainable construction." This agenda will highlight critical zones of attention intended for academics and specialists before determining if project management can evolve to become more sustainable, or if a more innovative approach is necessary ${ }^{[10]}$. 


\section{DISCUSSION}

The requirement is to evaluate sustainability has significantly enhanced the intricacy of trying to implement industrial and creation assignments, and additional organization practices have arisen over the last era to address international stability tasks, that require commitment and management of wider capabilities as of investors across the stock network. The innovative project administration model has been convoyed by a growing respect to the conception of business agreements in collaboration, sometimes referred to as partnering, which has evolved in construction and infrastructure projects as a means of improving project delivery. However, there are questions concerning the best method for fostering, integrating, and maintaining the necessary teamwork, particularly in road repair projects that use sustainable management practices. Established on a solo case history of an infrastructural preservations agreement comprising a large collaborative business arrangement, this paper resolves these issues. The findings show that various collaboration techniques have an impact on several areas of long-term project management. Furthermore, the wide collaborative business arrangement has facilitated long-term delivery based on organizational learning and improvement. As a result, this research provides a positive example of how widespread collaboration may be cultivated and played a major part in long-term project management techniques.

\section{CONCLUSION}

A review of literature on several aspects related to the sustainable element of managing projects has been offered in this work. From 1987 to 2018, the project management literature on sustainable construction was supplied for easy knowledge of the concerns, threats, possibilities, methodologies, and advantages of sustainability. In the study, famous academics identified and discussed several components of sustainability, as well as responsible policies and the criteria for selecting numerous methods to ensure sustainability into Know and Appreciate Significance of Sustainability. Planning a project Execution and control are two terms that are often used interchangeably. Project-Staff Training and Development ensure the project's long-term viability. Projects that are sustainable Project Manager Program Staff.

The Projects Company's Management Defining Policies for Project Sustainability Evaluation, Execution, and Control. Management of Stakeholders. Provide feedback on the projects. According to the review of literature, there is an opportunity for a new prospect for review and studies in the area of bearable project management such as follows: In the area of sustainable managing projects, computational processes and evolutionary algorithms can be used to estimate and use the optimal level of resources. Profitability, safety, transparency, ethicality, environmental friendliness, public acceptance, and meeting stakeholders' and clients' expectations are some of the 
important factors from sustainable construction that have been identified for use as considering variables in multi-objective proper project management issues to classify and evaluate sustainable development. A fully integrated model for monitoring and evaluating project management sustainability is developed and investigated, which involves the incorporation and assessment of feedback functions for every action, initiative, and policies taken by the organization. 


\section{REFERENCES}

[1] V. K. Chawla, A. K. Chanda, S. Angra, and G. R. Chawla, "The sustainable project management: A review and future possibilities," J. Proj. Manag., 2018, doi: 10.5267/j.jpm.2018.2.001.

[2] N. Wang, S. Yao, C. C. Wu, and D. Jiang, "Critical factors for sustainable project management in public projects," 2015.

[3] A. K. Munns and B. F. Bjeirmi, "The role of project management in achieving project success," Int. J. Proj. Manag., 1996, doi: 10.1016/0263-7863(95)00057-7.

[4] N. Wang, S. Yao, G. Wu, and X. Chen, "The role of project management in organisational sustainable growth of technology-based firms," Technol. Soc., 2017, doi: 10.1016/j.techsoc.2017.08.004.

[5] G. Silvius, "Sustainability as a new school of thought in project management," J. Clean. Prod., 2017, doi: 10.1016/j.jclepro.2017.08.121.

[6] A. H. A. Bakar, A. A. Razak, S. Abdullah, and A. Awang, "Project Management Success Factors for Sustainable Housing : A Framework," Asian J. Manag. Res., 2009.

[7] J. Kivilä, M. Martinsuo, and L. Vuorinen, "Sustainable project management through project control in infrastructure projects," Int. J. Proj. Manag., 2017, doi: 10.1016/j.jproman.2017.02.009.

[8] R. Schipper and G. Silvius, "The sustainable project management canvas," J. Mod. Proj. Manag., 2017, doi: 10.19225/JMPM01206.

[9] A. J. G. Silvius and R. Schipper, "Developing a maturity model for assessing sustainable project management," J. Mod. Proj. Manag., 2015, doi: 10.3963/jmpm.v3i1.112.

[10] R. C. Moehler, A. J. Hope, and C. T. Algeo, "Sustainable Project Management: Revolution or Evolution?," Acad. Manag. Proc., 2018, doi: 10.5465/ambpp.2018.13583abstract. 